Research Article

\title{
Flexural Capacity and Behavior of RC Hollow Bridge Beams after a Time Service of 24 Years
}

\author{
Guangzhen Qu $\mathbb{D}^{1,2}$ Guangli Zhou, ${ }^{2}$ Sizhong Lv, ${ }^{3}$ and Pingming Huang ${ }^{1}$ \\ ${ }^{1}$ School of Highway, Chang'an University, Xi'an 710064, China \\ ${ }^{2}$ Shandong Transportation Institute, Jinan 250012, China \\ ${ }^{3}$ Shandong Hi-Speed Co., Ltd., Jinan 250014, China \\ Correspondence should be addressed to Guangzhen Qu; quguangzhen@126.com
}

Received 14 April 2020; Revised 28 May 2020; Accepted 1 July 2020; Published 21 July 2020

Academic Editor: Chiara Bedon

Copyright (c) 2020 Guangzhen Qu et al. This is an open access article distributed under the Creative Commons Attribution License, which permits unrestricted use, distribution, and reproduction in any medium, provided the original work is properly cited.

\begin{abstract}
The residual bearing capacity of existing bridges has been a controversial topic for engineers and technicians. In order to accurately evaluate the actual bearing capacity of a 24-year-old RC hollow beam bridge, its components with different thickness concrete leveling layer were removed and transported back to the laboratory. The representative static and dynamic responses of the two beams were monitored during the whole procedure. A quick assessment of loading capacity of bridge using crack height and a parameter correction method for the crack width prediction formula in the code were proposed. In addition, comparison of measured and current design codes GB 50010 and ACI 318 predicted behaviour of existing beams was also presented. The results showed that the bending process of the RC hollow beam went through the elastic phase to the elastic-plastic phase and to the final failure. The actual flexural capacity of two beams was $10 \%$ larger than the calculated values. The natural vibration frequencies of the beam changed slightly before plastic stage, but the modal amplitude increased with the increase of degree of damage, once the beam entered plastic stage. The predicted deflections according to GB50010 were consistent with the experimental values at about $200 \mathrm{kN}$; for the code ACI, as the loading force increased, the difference between the two gradually decreased.
\end{abstract}

\section{Introduction}

For bridge structures, long service times and frequent traffic loads can lead to decreased stiffness and cumulative damage [1]. China's highway vehicle load standard has changed, upgrading from "Automobile-over 20" to the new code "Highway-I," which were published in 1989 and 2015, respectively. Current vehicle load levels often exceed the levels that bridges were designed for in earlier years, resulting in bridge overload [2]. It became especially important to accurately predict and understand the behavior of structures when loaded beyond service loads [3,4]. Failure testing of the structure is the most direct method for evaluating mechanical performance indicators like residual bearing capacity [5]. However, the destructive tests of full-scale structures are expensive and difficult to carry out. A few experimental studies are being carried out by scholars in different countries $[6,7]$.
Since the 1970s, a lot of studies have carried out failure testing research on the bearing capacity of full-scale bridges. Jorgensen and Larson conducted a failure test on a 10-yearold RC hollow slab bridge in North Dakota; the results showed that the actual bearing capacity of the bridge was much higher than the theoretical predictions [8]. Lantsoght et al. conducted a failure test on a RC hollow slab bridge in the Netherlands that had been in service for 52 years. The test result showed that the methods for rating existing RC hollow slab bridge are conservative [9]. Harries removed two box girder members from a 42-year-old RC box girder bridge and conducted failure tests to investigate the effect of strand corrosion on the flexural properties of the members [10]. Li et al. carried out an on-site failure test on an in-service T-beam bridge using an overload method; the force behavior of T-beam bridge during the test was analyzed [11].

Some authors made large-scale model specimens in the laboratory for bearing capacity tests. Paul et al. studied the 
mechanical behavior of a post-tensioned slab bridge under overload and ultimate load through model tests; the result showed that the ultimate experimental moment was 4.8 times the factored moment of an AASHTO MS 18 loading [12]. Bechtel et al. conducted a failure test on an I-type composite beam and performed finite element analysis using the ABAQUS program; the test results showed that the steel girder had a significant reserve capacity, and the response of the specimen was governed by the degradation of the RC bridge deck [13].

The above tests did not study the effect of concrete leveling layer on the bearing capacity of old bridges. Seible and Latham conducted research on the effective thickness of pavement; the study concluded that the bridge deck pavement can improve the bearing capacity of the main beam [14]. Tang et al. carried out a full-scale failure test of hollow slab to analyze the influence of pavement on deformation, and bearing capacity. The results showed that the girder and pavement work together well due to the bond between them. A $10 \mathrm{~cm}$-thick concrete pavement could increase the ultimate bearing capacity by $25 \%$ [15]. However, research on the influence of bridge pavement after many years of service was less.

In this paper, two dismantle hollow beam components after service for 24 years were tested to failure to investigate actual flexural capacity, and the static performance (such as deflection, strain, and cracks development) was recorded during loading; the effect of concrete leveling layer on the flexural performance was discussed. The comparison between the actual measurement and the predicted performance of the existing beams was presented.

\section{Experimental Program}

2.1. Background of the Project. The testing beams were originally located on Jinan-Qingdao Expressway, which is known as the Golden Path of Shandong Province. The expressway, the first in Shandong Province, was completed in 1993. It is the busiest traffic pathway in Shandong. According to incomplete statistics in 2015, 2.2 million vehicles passed throughout the year, including about 400,000 vehicles with 6 axles and above. The expressway needs to be expanded to accommodate more traffic. In this process, a 24year $8 \mathrm{~m}$-span RC hollow beam was dismantled from the bridge and transported back to the laboratory for failure testing to evaluate its residual bearing capacity.

The designed height of the testing beams was $40 \mathrm{~cm}$, and bridge deck was paved with a $10 \mathrm{~cm}$ concrete leveling layer. Later, an additional $7 \mathrm{~cm}$ concrete leveling layer was paved for overall road elevation at one side of the central reservation. During on-site construction, the wire saw cut down vertically from joint concrete, so the experimental beams have partially joint concrete. The integrated process of onsite cutting, demolition, transportation, and laboratory storage of the RC hollow beam is shown in Figure 1. Typical cross section of the original bridge is shown in Figure 2.

2.2. Test Specimen. Two experimental beams were selected, and they were numbered JD1 and JD2. The difference between them was the thickness of the leveling layer, which was
$170 \mathrm{~mm}$ and $100 \mathrm{~mm}$, respectively. The cross section of the tested beams is shown in Figure 3.

The designed strength grade for the concrete was C25. The bottom longitudinal rebars of the beam were of $25 \mathrm{~mm}$ diameter with spiral ribbing, and the stirrups and top construction rebars used plain round steel with $8 \mathrm{~mm}$ diameter. The material parameters of concrete and rebar are shown in Tables 1 and 2, respectively [16].

The hollow beam was inspected before testing as shown in Figure 4. There were a few cracks on the bottom of the beams, and the largest width of the cracks was $0.1 \mathrm{~mm}$. There was no obvious rust on the longitudinal tensile rebars. The strength of the beam was calculated using the rebound method, and the evaluated strength value was 25.3 MPa.

2.3. Test Scheme. The beams were simply supported and tested under a four-point bending configuration. The clear span and shear span were 7.62 and $2.81 \mathrm{~m}$, respectively. Two monotonic concentrated loads were applied to the beams by the hydraulic actuator and spreader beams. The applied loads were monitored and recorded through a load cell and electronic data logger. Displacement gauges were installed at the middle span, at the one-fourth span position, and at both ends of the beam. The concrete strain gauges were placed in the midspan web surface of the beam, and the bottom concrete at the reinforcement location was cut out to place the rebar strain gauges. The appearance and propagation of the cracks were observed visually, and a digital crack-width viewer was used to measure the crack widths. The vibration sensors were arranged on the top plate of the hollow beam to collect the modal information. The beam details and experimental setup are shown in Figure 5, and an overview photograph of the JD1 test setup is shown in Figure 6.

2.4. Termination Condition. The component failed when one of the following conditions appeared [17]:

(1) The main tensile reinforcement was broken

(2) The bending deflection reached $1 / 50$ of the span

(3) The crack width at the tensile reinforcement reached $1.5 \mathrm{~mm}$

(4) The strain of the reinforcement reached 0.01

(5) There was cracking and crushing of concrete in compression area

\section{Experimental Results}

3.1. Test Phenomena. In the process of the test, data were collected synchronously through pressure sensors, displacement sensor, and strain collection device. The distribution of crack development after component failure in JD1 and JD2 is shown in Figure 7. Considering a JD1 hollow beam as an example, it can be seen that there are five original cracks in the constant moment region of the beam before loading, and the original crack height was small and the maximum width was $0.1 \mathrm{~mm}$. As the experimental load increases, the number of cracks in the test beam increased, 


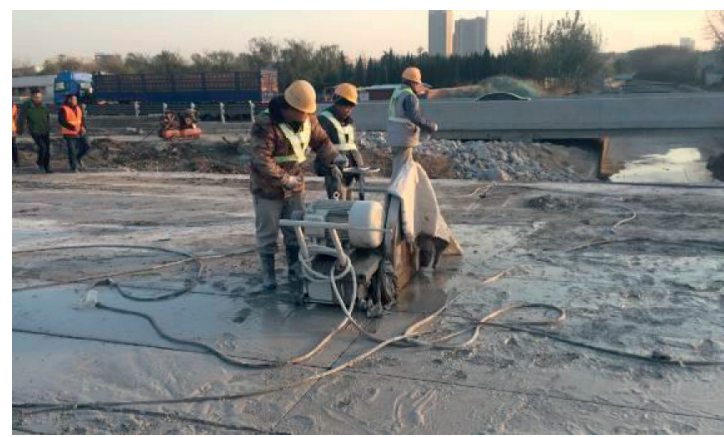

(a)

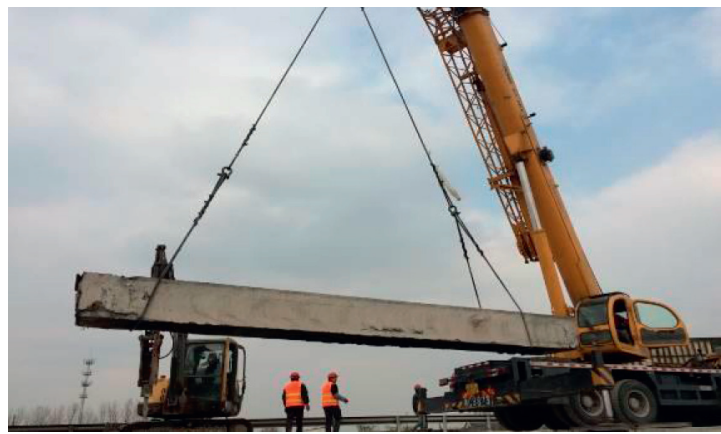

(c)

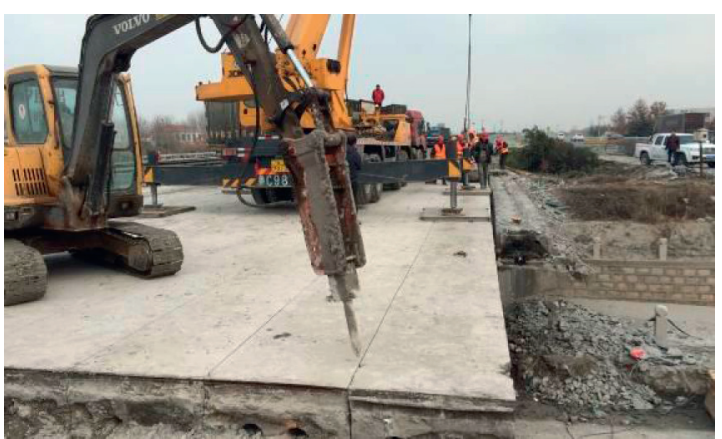

(b)

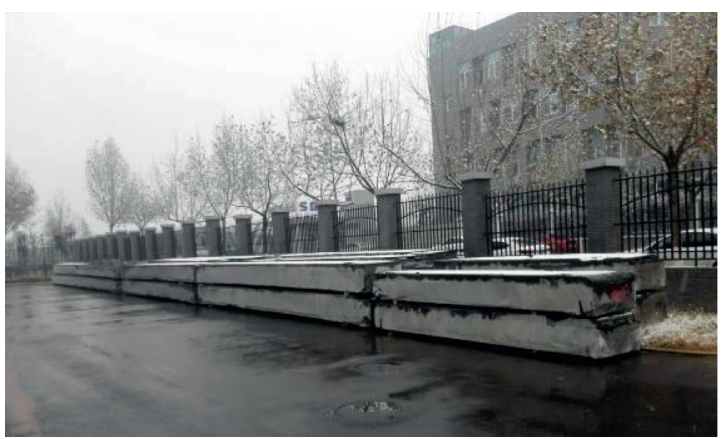

(d)

Figure 1: In situ construction: (a) cutting; (b) demolish; (c) lifting; (d) storage.

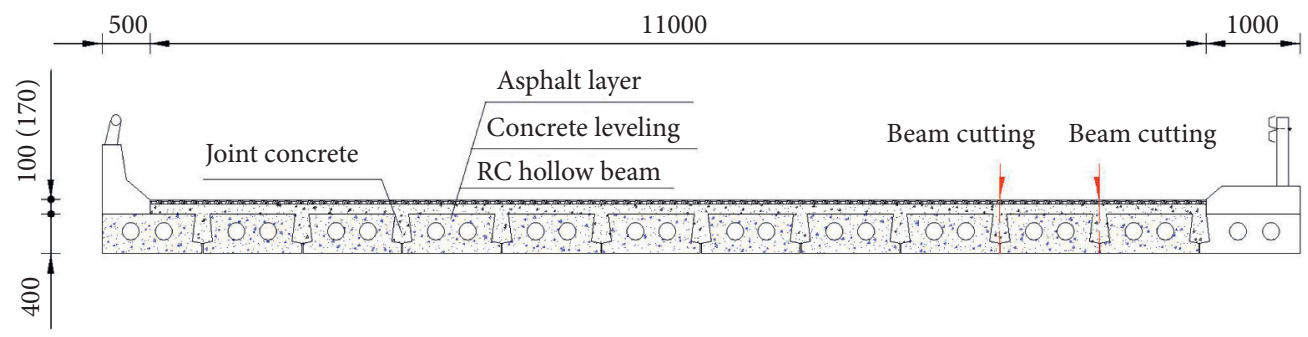

Figure 2: Cross section of the original bridge (unit: $\mathrm{mm}$ ).

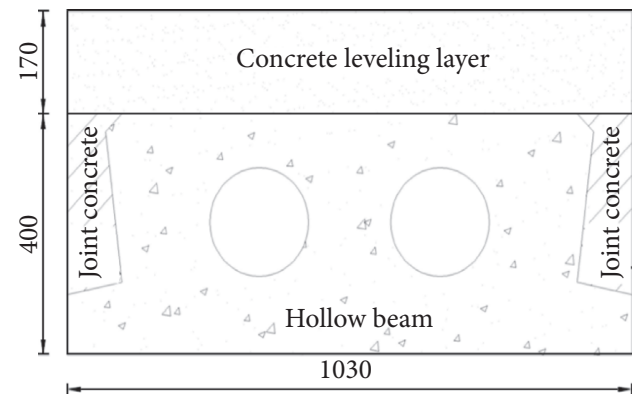

(a)

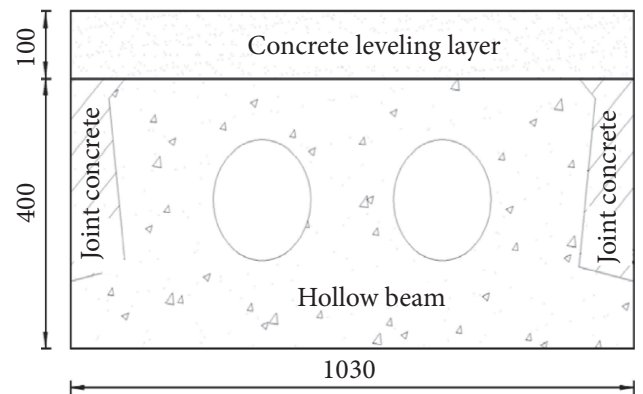

(b)

FIgURE 3: Cross section of the tested beams: (a) JD1; (b) JD2 (unit: mm).

TABLE 1: Material properties of C25 concrete.

\begin{tabular}{ccccc}
\hline & Compressive strength, $f_{c}(\mathrm{MPa})$ & Tensile strength, $f_{t}(\mathrm{MPa})$ & Elastic modulus, $E_{c}(\mathrm{GPa})$ & Density $\left(\mathrm{kg} / \mathrm{m}^{3}\right)$ \\
\hline $\mathrm{C} 25$ & 14.5 & 1.90 & 28.5 & 2400
\end{tabular}


TABLE 2: Material properties of rebar.

\begin{tabular}{lccc}
\hline & Tensile strength, $f_{\mathrm{s}}(\mathrm{MPa})$ & Elastic modulus, $E_{s}(\mathrm{GPa})$ & Density $\left(\mathrm{kg} / \mathrm{m}^{3}\right)$ \\
\hline$\phi 25$ & 340 & 200 & 7800 \\
$\phi 8$ & 240 & 210 & 7800 \\
\hline
\end{tabular}

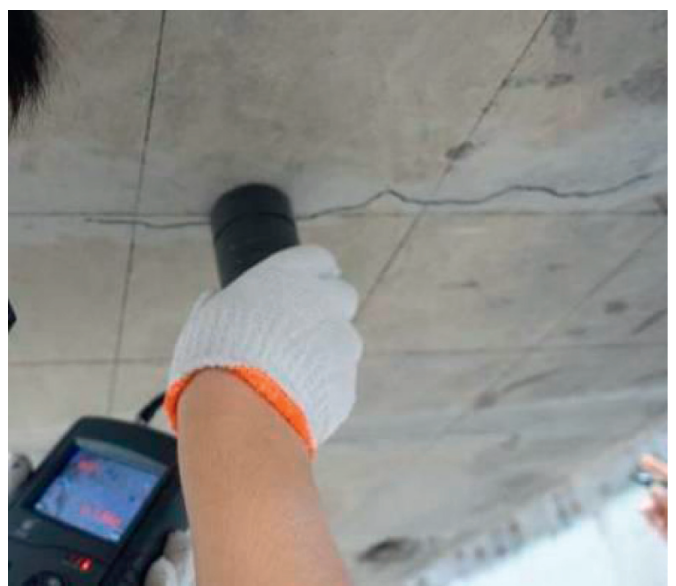

(a)

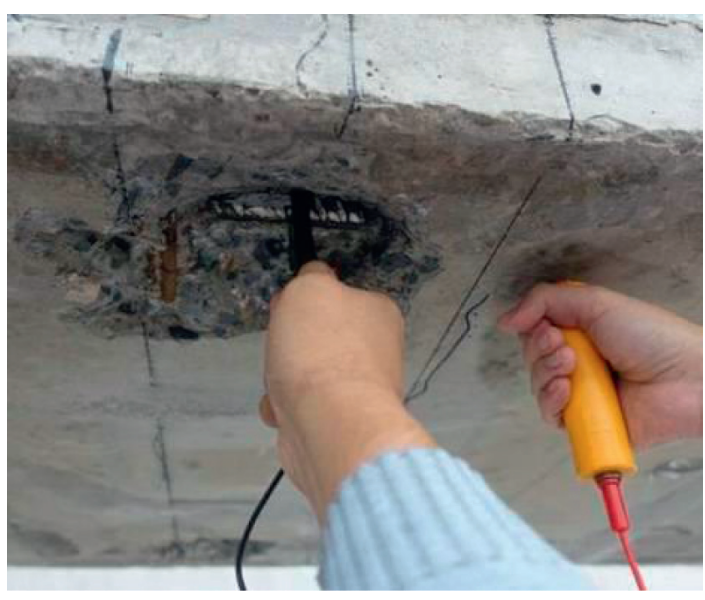

(b)

FIGURE 4: Pretest detection: (a) crack width; (b) corrosion of reinforcement.
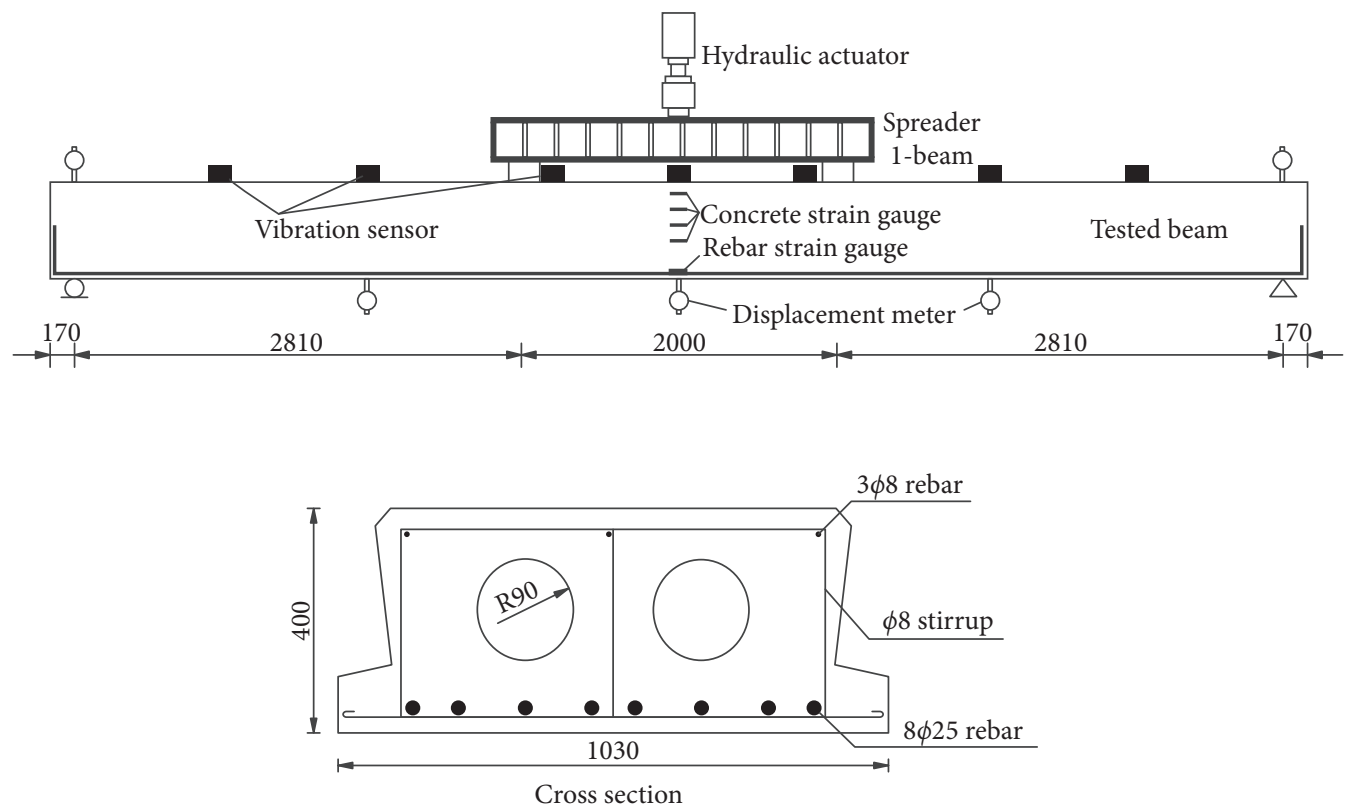

Figure 5: Beam details and experimental setup (unit: $\mathrm{mm}$ ).

and the crack width and height increased. Before the longitudinal tensile rebar entered the yield phase, the components showed good elasticity and the load-deflection curve showed a linear relation; the width of the crack grew relatively slowly and remained within $0.5 \mathrm{~mm}$, and the crack was essentially closed after unloading. With loading to approximately $0.9 P_{u}$, the longitudinal tensile rebar entered the yield phase, and the deflection reached approximately $1 /$ 400th of the calculated span. At this phase, the load increased gradually, whereas the mid-span deflection increased rapidly. With the continuous increase in load, the number of cracks no longer increased, the crack distribution was more uniform, and the neutral axis continued moving upwards until the strain of rebar exceeded the limit strain of 0.01 . The concrete in the compression zone of JD1 was not crushed, while that of JD2 was crushed (Figure 8). 


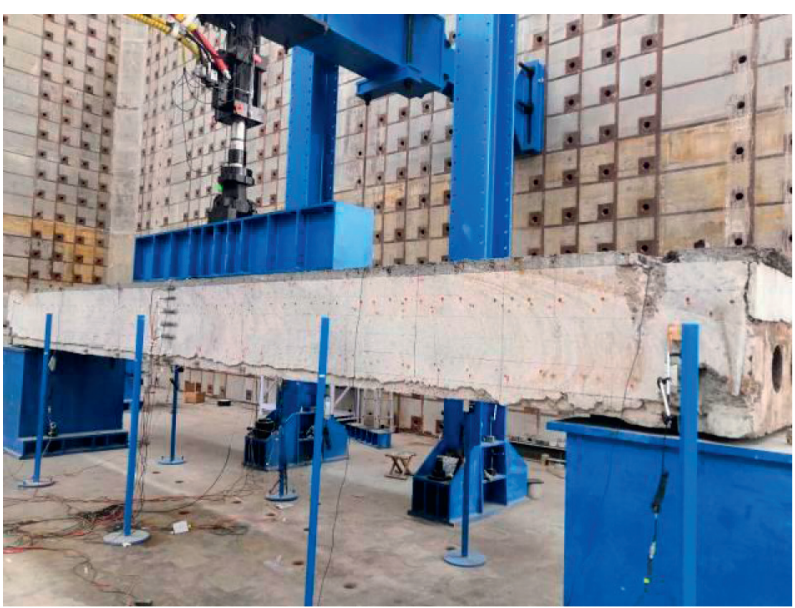

FIGURE 6: Overview of JD1 test setup.

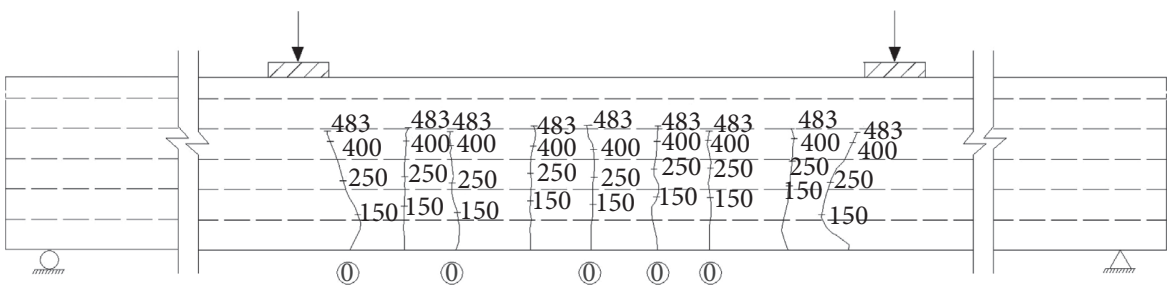

(a)

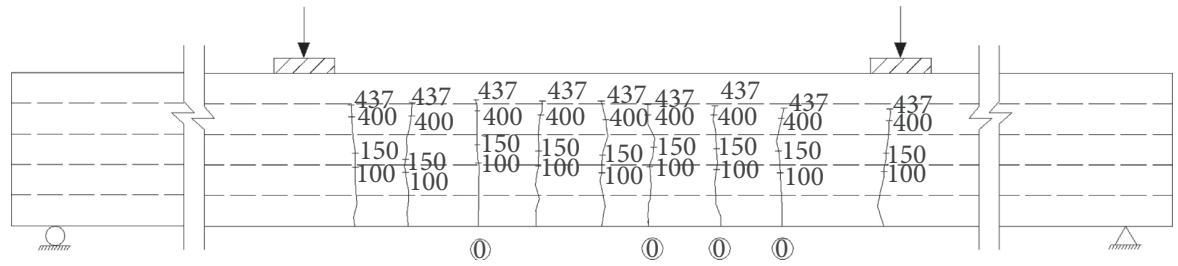

(b)

FIGURE 7: Distribution pattern of web cracks: (a) JD1; (b) JD2.

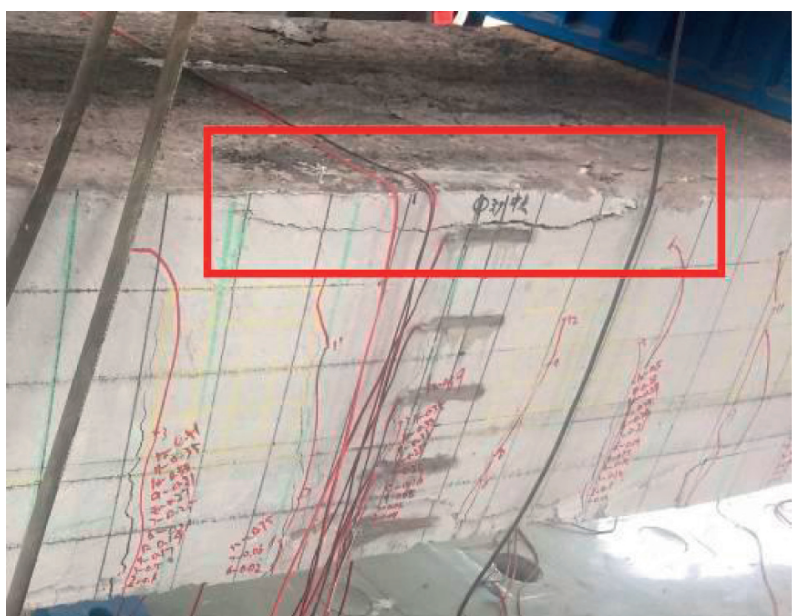

Figure 8: The failure of JD2: crushed concrete. 
3.2. Analysis of Beam Deflection and Ductility. The deflection curves of the different measuring points along the span of beams are shown in Figure 9. The deflections of the entire beams were basically symmetrical to the mid-span section. When the loading force for JD1 and JD2 was $445 \mathrm{kN}$ and $400 \mathrm{kN}$, respectively, the deflection of mid-span and onefourth span section increased greatly.

The load-midspan deflections of the tested beams are shown in Figure 10. The law of the load-deflection curve for each beam was consistent and was in a typical twofold line change pattern. The load-deflection curves changed linearly at the beginning of loading, which indicates that the beams are in an elastic working state. As the load increased, the deflection increased suddenly, the slope of the load-deflection curves changed abruptly, and the longitudinal tensile rebars entered the yielding phase. After the yielding phase, the load-deflection curves were close to horizontal, such that a small increase in load may cause a rapid increase in displacement.

The development of the internal damage done to the beams directly corresponds with residual deflection. Considering JD1 as an example, when the component was in the elastic phase, the residual deflection was within $0.7 \mathrm{~mm}$ after unloading. When the longitudinal tensile rebars yielded, the component entered the plastic phase, and the residual deflection reached $2.7 \mathrm{~mm}$ after unloading. After component failure, the residual deflection after unloading reached $21.2 \mathrm{~mm}$.

The mechanical property parameters of the tested beams are shown in Table 3 . The additional $7 \mathrm{~cm}$ leveling layer, present in JD1 and JD2, increased the yield and ultimate load of the component by about $11 \%$ and reduced the yield and ultimate deflection by $22 \%$ and $17 \%$, respectively.

The displacement ductility values, $\mu$, of the specimens were calculated using the following formula $[18,19]$ :

$$
\mu=\frac{f_{u}}{f_{y}} .
$$

The values of $f_{u}$ and $f_{y}$ are shown in Table 3. The displacement ductility values of JD1 and JD2 are 2.22 and 2.08, respectively.

3.3. Strain and Stress Analysis. During the loading process, the average strain on the rebar and concrete in the midspan section of the beam was taken to be representative of the corresponding strain. The load-rebar strain curves are shown in Figure 11. Considering JD1 as an example, the strain of the rebar changed approximately linearly with the load increase before the yield phase. When the load reached $445 \mathrm{kN}$, the rebar entered into the yield phase, and the strain of the rebar was $1567 \mu \varepsilon$ with a residual strain of $429 \mu \varepsilon$ after unloading. When the load was $483 \mathrm{kN}$, the strain reached $11094 \mu \varepsilon$. At this time, the strain of rebar had exceeded the limit strain of 0.01 . Therefore, it was believed that the testing load had reached the ultimate failure load, and the residual strain of the rebar after unloading was $9346 \mu \varepsilon$. The load increased by less than $10 \%$ from rebar yield to component failure.
The lateral concrete strain of RC beams changed along the height of the beam, as shown in Figure 12. With the increase of the loading force, the crack continued to extend upward, and the bottom strain gauge gradually failed. For JD2, when the load exceeded $350 \mathrm{kN}$, only one strain gauge at the top worked normally. The concrete strain in the compression zone of JD2 was significantly larger than that of JD1 under the same load. At the end of the test, the maximum compressive strain of JD1 was $350 \mu \varepsilon$, while that of JD2 was $778 \mu \varepsilon$; at this point the top concrete of JD2 was crushed. The height of the neutral axis that can be obtained from the web concrete strain kept rising during the test, as shown in Figure 13. When the load was within $200 \mathrm{kN}$, the position of the neutral axis changed rapidly, which can be attributed to the sharp growth of vertical cracks.

3.4. Crack Development. After test beam failure, about ten cracks were generated in the constant moment region, and the average longitudinal distance of the cracks was $20 \mathrm{~cm}$, which are generated at the stirrup position. Two cracks were selected from the two beams for crack width analysis, as shown in Figure 14. It can be seen that the width of cracks increased as the load increased, the crack width grew relatively slowly and remained within $0.5 \mathrm{~mm}$ before the rebar entered the yield phase, and the crack was essentially closed after unloading in this phase. The growth rate of the crack width accelerated significantly after the rebar entered the plastic phase, where the crack did not close after unloading. After the beams failed, the biggest crack width was about $2.0 \mathrm{~mm}$ during loading and about $1.1 \mathrm{~mm}$ after unloading for two beams.

Two cracks were selected from the two beams for crack height analysis, as shown in Figure 15. The crack height increased rapidly below $200 \mathrm{kN}$; this cracking of the concrete was in the tensile zone away from the neutral axis [20]. When the crack height approached the central axis, the cracking speed slowed, and the load increased significantly towards the yield of the rebar. After this point, the crack height increased slowly until it reached the ultimate load. When the beams were in failure, the web vertical cracks extended to the bottom of the concrete leveling layer.

It can be seen from the development of crack height under different loading forces (Figures 7 and 15), for the JD1 beam, when the crack height developed to 0.66 to 0.70 times the beam height, the steel bar entered the yield stage; for the JD2 beam, when the crack height developed to 0.72 to 0.75 times the beam height, the steel bar entered the yield stage. Therefore, if the crack height reached 0.70 times the beam height, the steel bar may enter the yield stage and the bridge should be accurately diagnosed and repaired in time [21].

3.5. Full-Process Modal Analysis. The JD1 beam was subjected to modal tests after unloading 7 times during the failure test in order to analyze the change of the dynamic characteristics from the initial state to the failure state [22]. Changes in the first three-order natural frequency of the hollow beam corresponding to the 7 th modal test are shown in Figure 16. It can be seen that before the hollow beam 


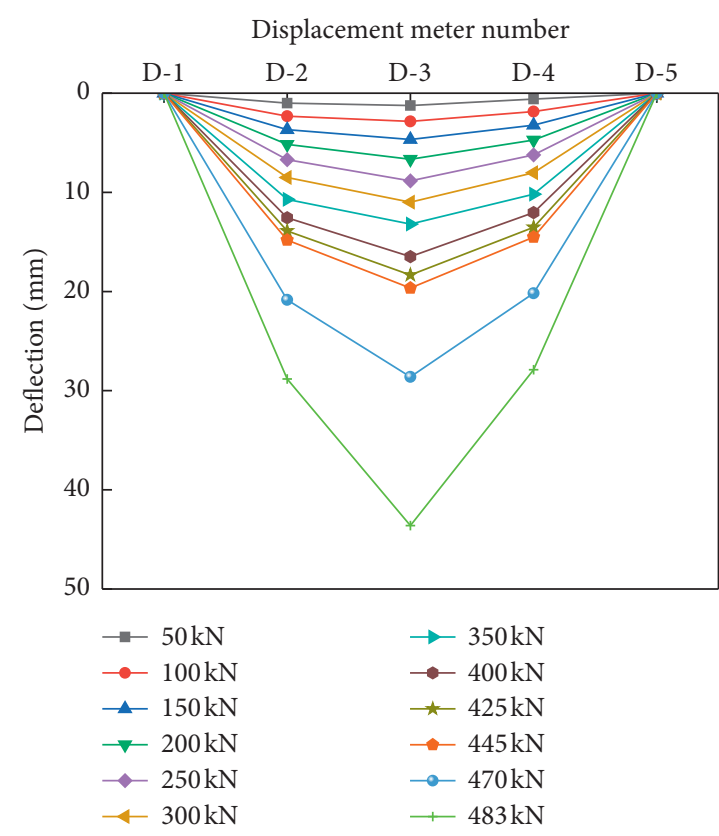

(a)

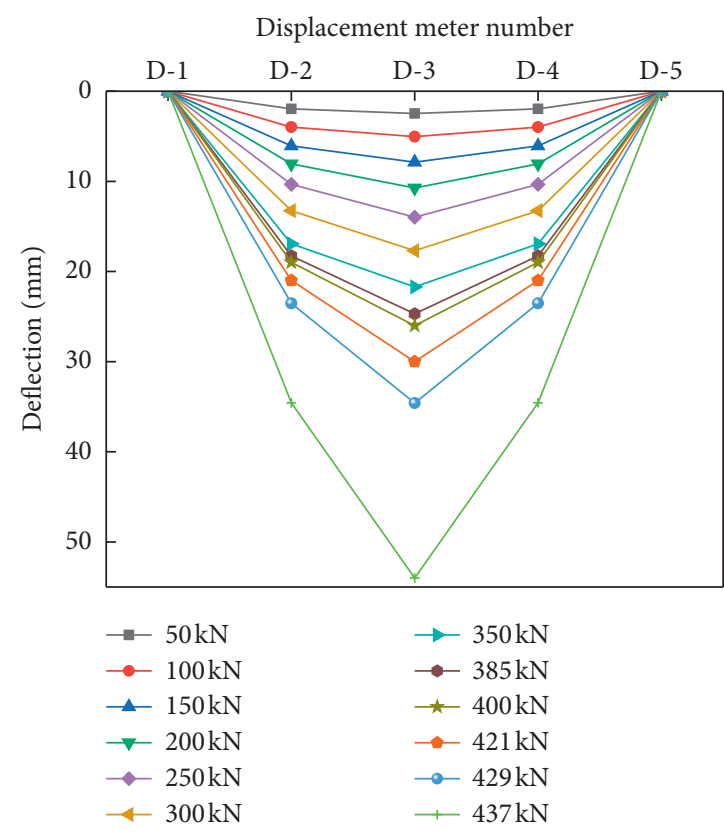

(b)

Figure 9: Load-deflection curves: (a) JD1; (b) JD2.

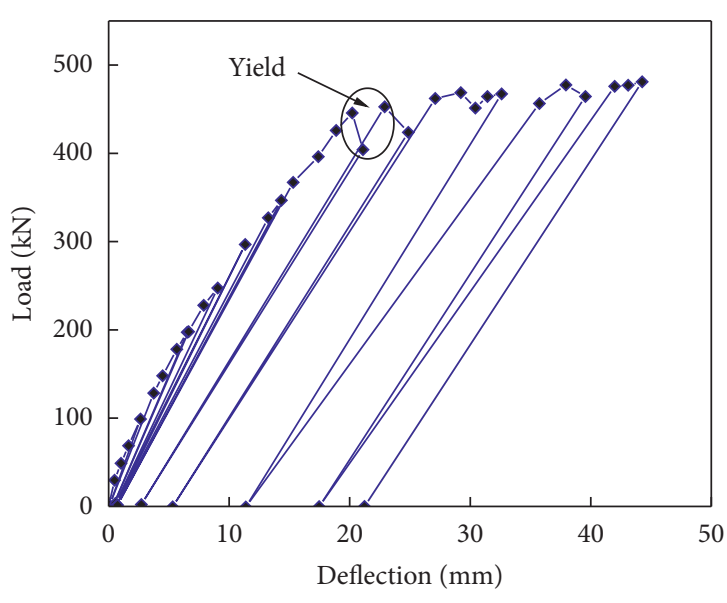

(a)

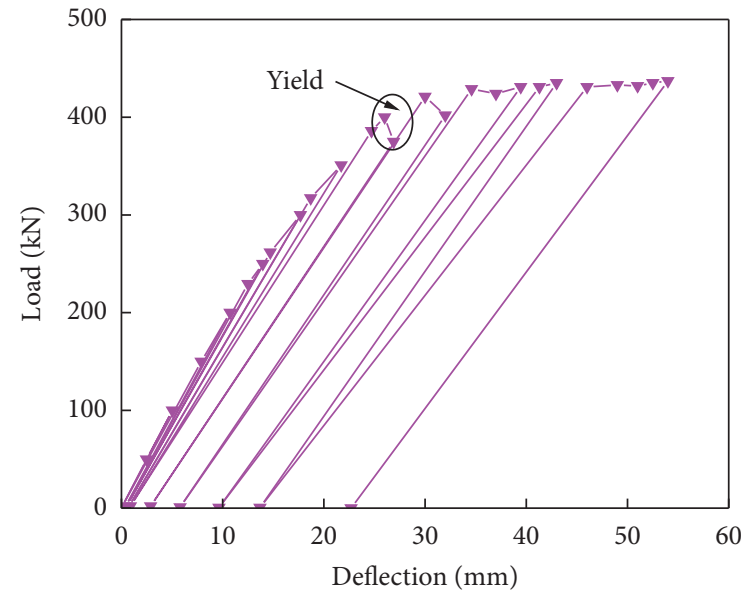

(b)

FIgURE 10: Load-midspan (residual) deflection curves: (a) JD1; (b) JD2.

TABle 3: Mechanical properties of tested beams.

\begin{tabular}{lcccc}
\hline Specimen number & Yield load $P_{y}(\mathrm{kN})$ & Ultimate load $P_{u}(\mathrm{kN})$ & Yield deflection $f_{y}(\mathrm{~mm})$ & Ultimate deflection $f_{u}(\mathrm{~mm})$ \\
\hline JD1 & 445 & 483 & 20.26 & 44.96 \\
JD2 & 400 & 437 & 26.02 & 54.11 \\
\hline
\end{tabular}

entered the plastic stage, its first-third-order natural vibration frequency changed slightly, but after entering the plastic stage, the first third-order frequency of the hollow beam significantly decreased, which means that, in the actual maintenance testing, once the modal characteristics of the structure or member changed obviously, the structure should be accurately diagnosed and repaired.

\section{Theoretical Analysis and Design Calculation}

4.1. Beam Deflection. For simply supported RC beam, the process of calculating deflection requires calculating the average stiffness throughout the beam length. The calculation formula of the midspan deflection under short term load is shown as follows: 


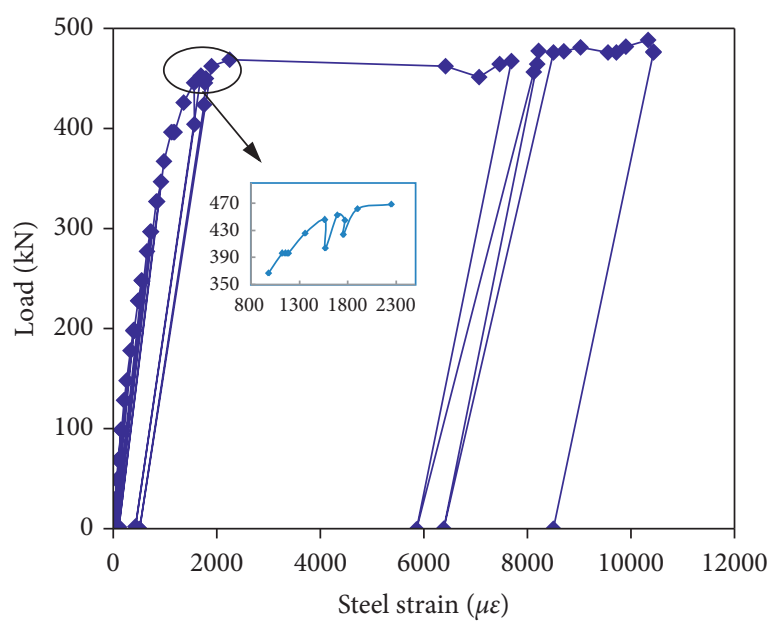

(a)

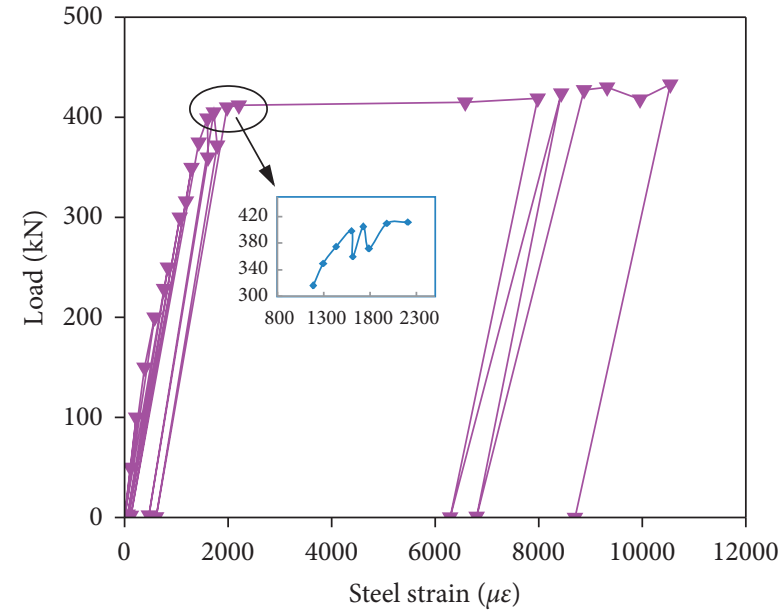

(b)

FIGURE 11: Load-rebar strain curve: (a) JD1; (b) JD2.

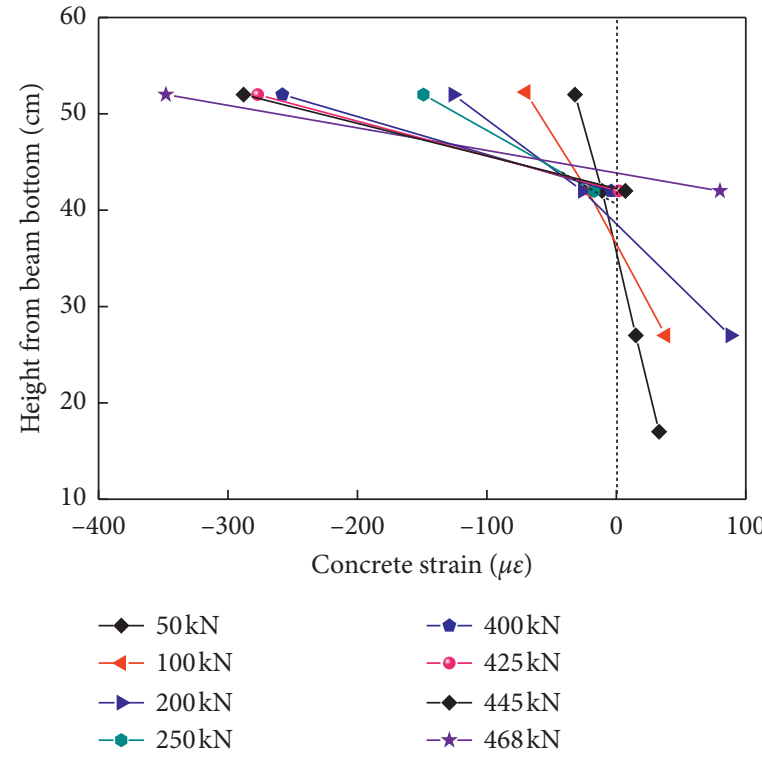

(a)

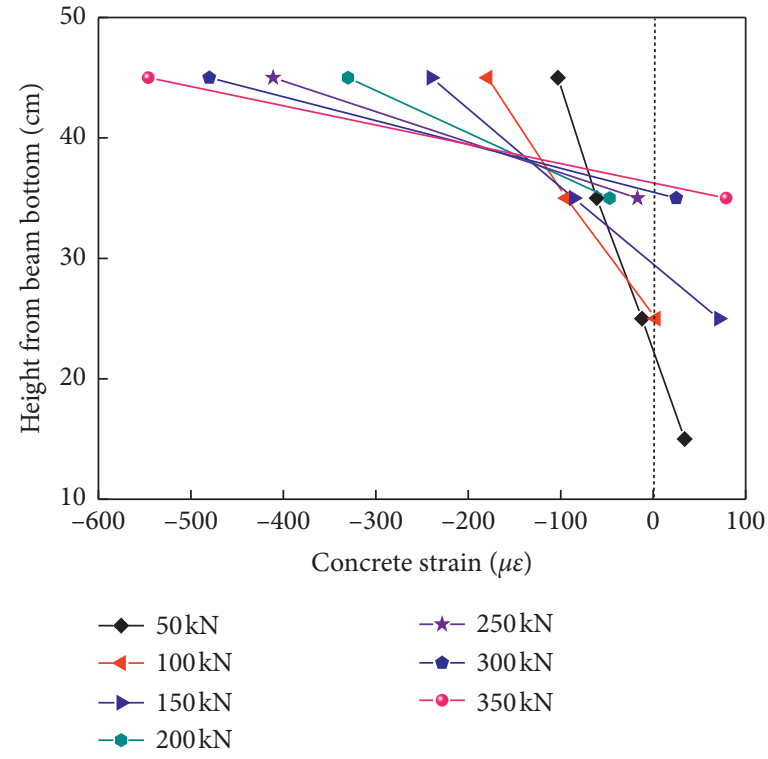

(b)

FIGURE 12: Distribution of concrete strain along section height: (a) JD1; (b) JD2.

$$
f=\frac{P a}{48 A}\left(3 L^{2}-4 a^{2}\right)
$$

where $P$ is the applied concentrated load; $a$ is the shear span of the beam; $L$ is the clear span of the beam; and $A$ represents the average stiffness of the beam, which is $B_{s}$ in Chinese code GB50010, and is the product of the elastic modulus of the concrete $\left(E_{c}\right)$ and the effective moment of inertia $\left(I_{e}\right)$ in ACI318 [23, 24].

At load $P=170 \mathrm{kN}$, which corresponds to the new code "Highway-I" vehicle load [25], the predicted deflections according to the two design codes (GB50010, ACI 318) and the measured (EXP) deflections are shown in Table 4. As shown in the table, the predicted deflections according to GB50010 were close to the experimental values. The predicted results of ACI318 are 29.2\% and 14.6\% larger than tested values for JD1 and JD2.

The predicted deflections according to the two design codes and the measured deflections at different load are shown in Figure 17. As shown in the table, the predicted deflections according to GB50010 were consistent with the experimental values at about $200 \mathrm{kN}$; for the code ACI, as the 


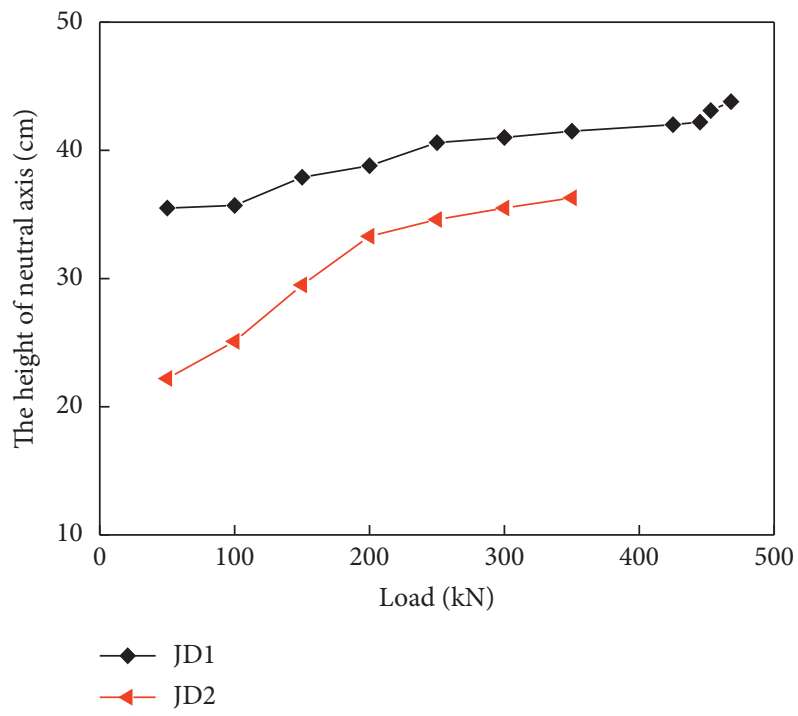

Figure 13: Height-load variation corresponding to the neutral axis.

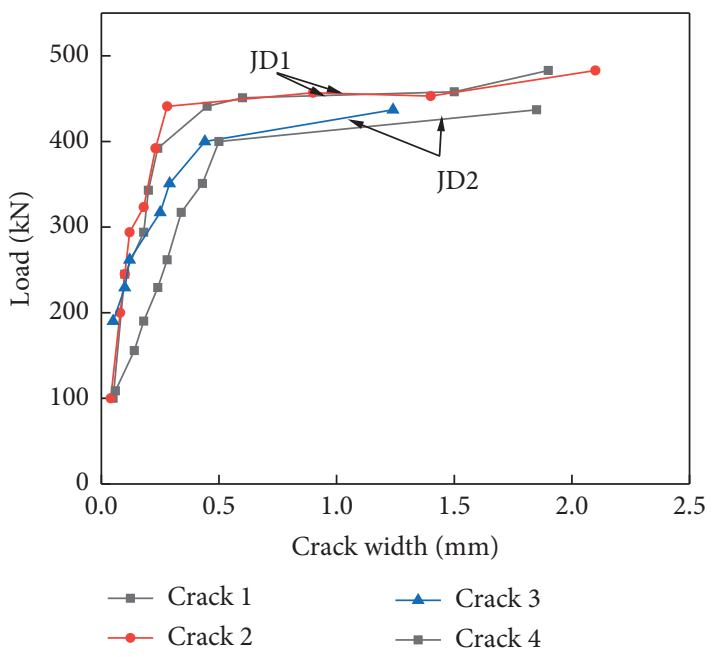

FIGURE 14: Load-crack width curves of JD1 and JD2 beams.

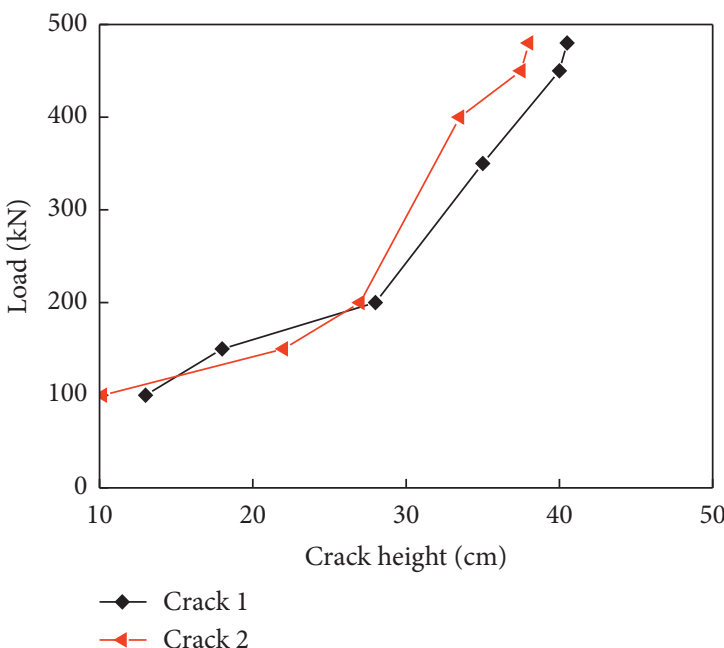

(a)

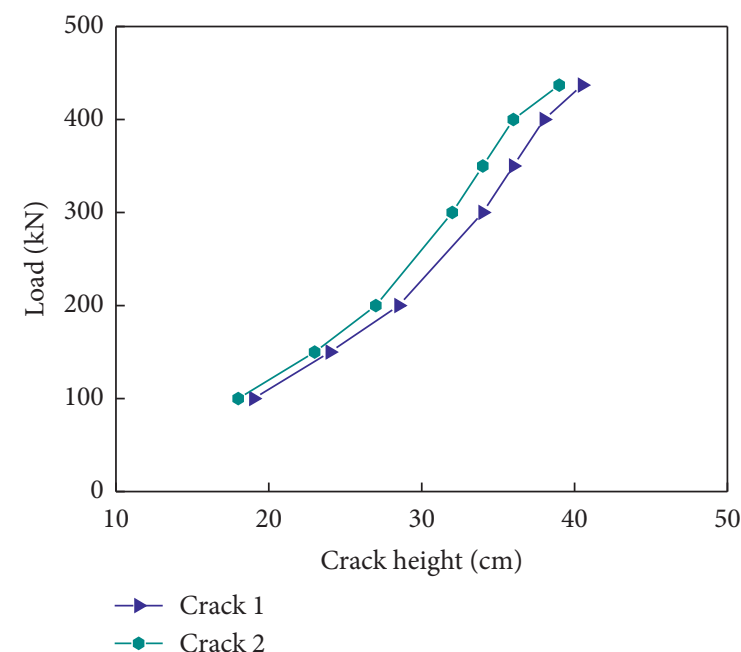

(b)

FIgURE 15: Load-crack height curves: (a) JD1; (b) JD2. 


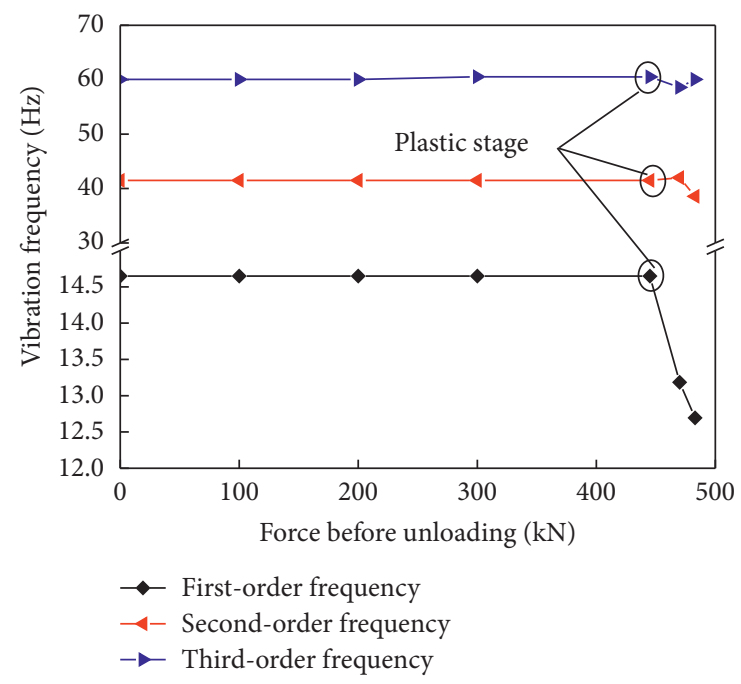

FIGURE 16: First three-order vibration frequency of JDlbeam.

TABle 4: Comparison of experimental and code predicted beam deflection at $170 \mathrm{kN}$.

\begin{tabular}{|c|c|c|c|c|c|}
\hline \multirow{3}{*}{ Specimen } & \multicolumn{5}{|c|}{ Beam deflection $(\mathrm{mm})$} \\
\hline & \multicolumn{5}{|c|}{ At $170 \mathrm{kN}$} \\
\hline & EXP & GB & $\mathrm{ACI}$ & (GB-EXP)/EXP (\%) & (ACI-EXP)/EXP (\%) \\
\hline JD1 & 5.66 & 6.03 & 7.31 & 6.5 & 29.2 \\
\hline JD2 & 9.08 & 8.96 & 10.41 & -1.3 & 14.6 \\
\hline
\end{tabular}

loading force increases, the difference between the two gradually decreases.

4.2. Crack Width. In GB 50010, the maximum probability crack width may be calculated according to the following formulae:

$$
\begin{aligned}
\omega_{i} & =\alpha_{\mathrm{cr}} \varphi \frac{\sigma_{s}}{E_{s}}\left(1.9 c_{0}+0.08 \frac{d}{\rho_{\mathrm{te}}}\right), \\
\varphi & =1.1-0.65 \frac{f_{t}}{\rho_{\mathrm{te}} \sigma_{s}},
\end{aligned}
$$

where $\alpha_{\mathrm{cr}}$ is the coefficient of the stress characteristic, which is 1.9 for RC beams; $\sigma_{s}$ is the longitudinal tensile rebar stress; $c_{0}$ is the clear cover; $d$ is the diameter of reinforcing bar; and $\rho_{\text {te }}$ is the reinforcement ratio of the rebars on the basis of the effective cross-sectional area of concrete.

The maximum probable crack width may be calculated according to formula (5) from ACI318.

$$
\omega_{i}=11.02 r \sigma_{s} \sqrt[3]{c_{0} A} \times 10^{-6}
$$

where $\sigma_{s}$ is the stress in reinforcing steel; $A$ is the effective area of concrete surrounding a rebar; and $r$ is the ratio of $h_{2}$ (the distance from the neutral axis to the extreme tensile fiber) to $h_{1}$ (the distance from the neutral axis to the centroid of the tension reinforcement).
According to the codes GB50010 and ACI318, the comparison between the maximum crack width obtained by the test (EXP) and the predicted results at the two load levels is shown in Table 5. The results show that the GB50010 approach, in general, underestimates the crack width by $51 \%$ at low levels $(150 \mathrm{kN}$ ) and $27 \%$ (on average) at high levels $(250 \mathrm{kN})$. The ACI318 approach underestimates the crack width by $33 \%$ at low levels and $39 \%$ (on average) at high levels.

The predicted maximum crack width according to the two design codes and the measured values at different load are shown in Figure 18. The maximum crack width predicted by the two codes was quite different from the test value, so the average deviation was taken as the correction coefficient of formulae (3) and (5) in this paper, respectively, and their values were $k_{\mathrm{GB}}=1.23$ and $k_{\mathrm{ACI}}=1.34$ [26].

4.3. Ultimate Capacity. Based on the following three basic assumptions, the ultimate flexural capacity of the normal section of the concrete hollow slab was calculated [27]:

(1) The plane section assumption was retained

(2) The tensile strength of concrete and top construction reinforcement were not considered

(3) All materials are in elastic working condition

To simplify the calculation, according to the principles of equal area and overlapping the centers of gravity, the cross 


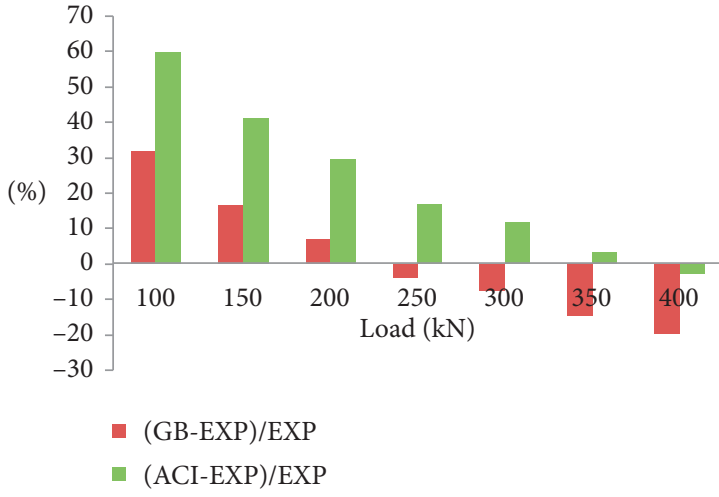

(a)

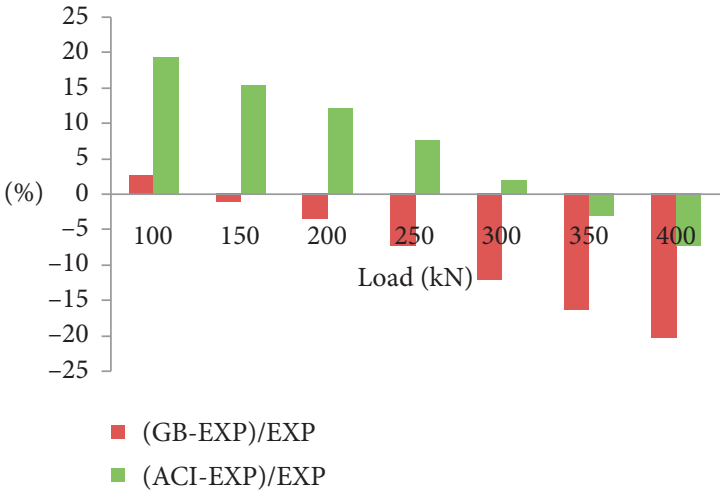

(b)

Figure 17: Comparison of experimental and code predicted beam deflection at different loads.

TABLE 5: Comparison of experimental and ACI predicted maximum crack width.

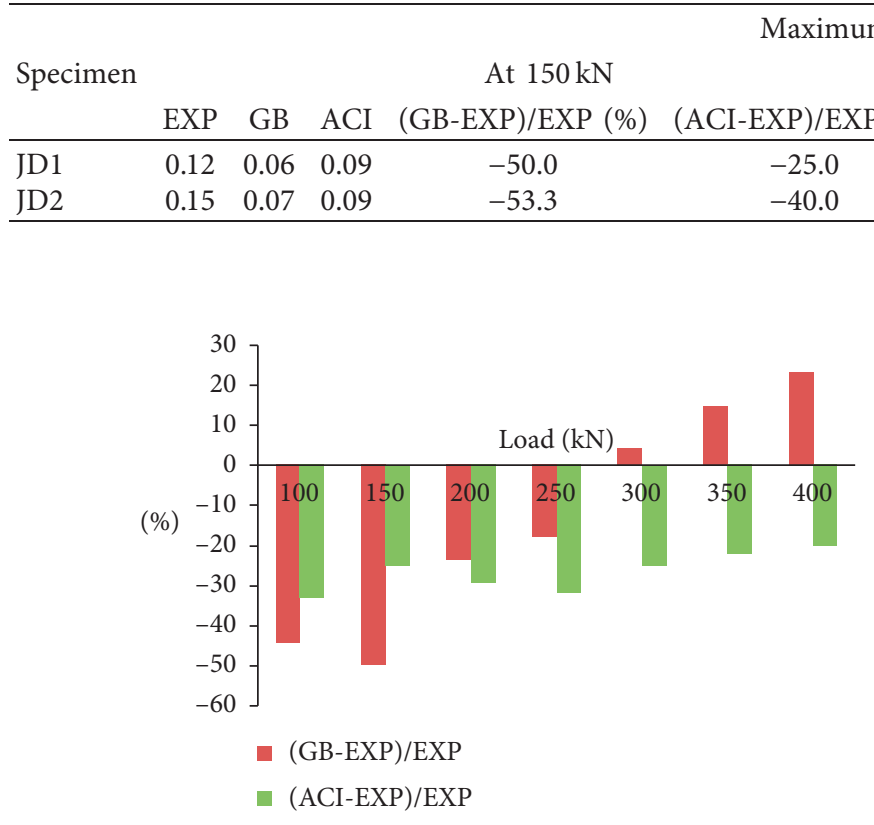

(a)

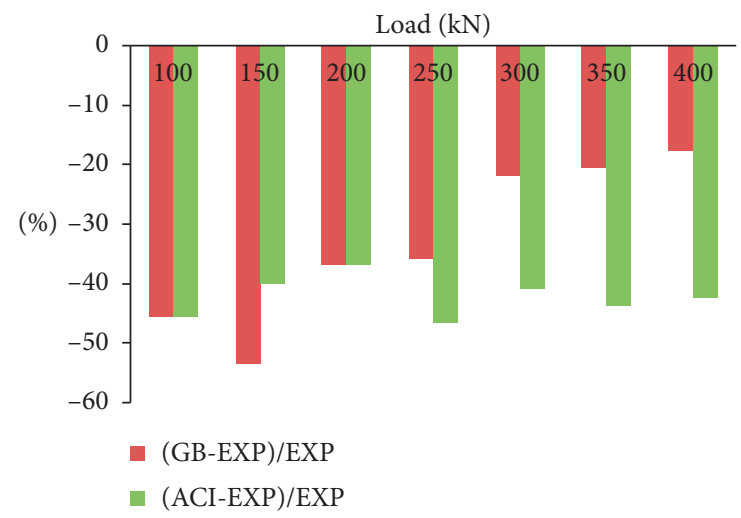

(b)

FIGURE 18: Comparison of experimental and ACI predicted maximum crack width at different loads: (a) JD1; (b) JD2.

section of hollow beam was converted into an I-shaped section, as shown in Figure 19.

$$
\begin{aligned}
b_{k} \times h_{k} & =\frac{\pi}{4} D^{2}, \\
\frac{1}{12} b_{k} \times h_{k}^{3} & =\frac{\pi}{64} D^{4} .
\end{aligned}
$$

Based on the principle of equal concrete compressive stress resultant $C$ and unchanged applied point position, the bending stress distribution model of the section was established, as shown in Figure 20, where $h$ is the height that includes the concrete leveling layer $[23,28]$.

The calculated values of moment capacity $\mathrm{Mu}$ were obtained through the following formulae:
At $250 \mathrm{kN}$

$\begin{array}{lllll}0.22 & 0.18 & 0.15 & -18.2 & -31.8 \\ 0.28 & 0.18 & 0.15 & -35.7 & -46.4\end{array}$

$\sum X=0, \quad f_{c} b x=f_{s} A_{s}$,

$\sum M=0, \quad M_{u}=f_{s} A_{s}\left(h_{0}-\frac{x}{2}\right)$,

where $b$ is width of cross section; $x$ is the height of compression zone; $A_{s}$ is the area of reinforcing bar; and $h_{0}$ is distance from extreme compression fiber to centroid of tension reinforcement.

The comparisons between the experimental (EXP) flexural capacity of the hollow beam and the calculated (CAL) values are shown in Table 6. As shown in the table, the actual flexural capacity was $10 \%$ larger than the calculated values. 


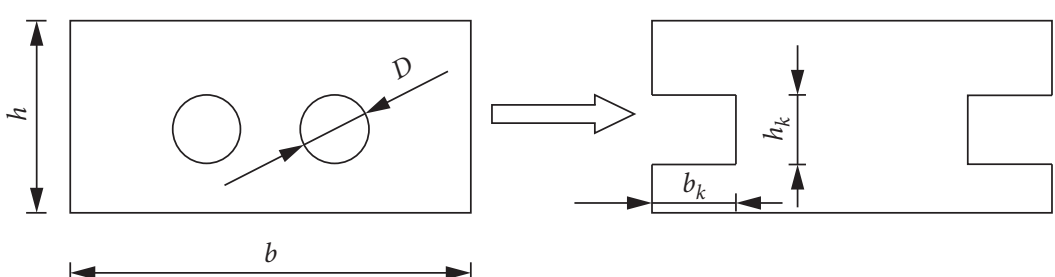

FIGURE 19: Reduced calculation model.
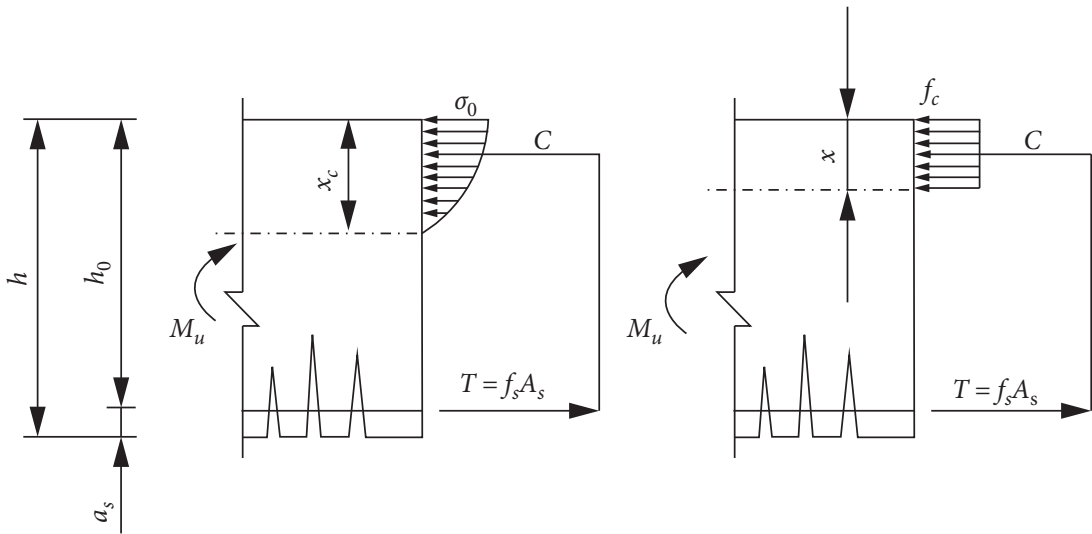

Figure 20: Distribution of bending stress on the cross section.

TABLe 6: Comparison of experimental and calculated ultimate flexural capacity.

\begin{tabular}{lccc}
\hline \multirow{2}{*}{ Specimen } & \multicolumn{3}{c}{ Ultimate capacity $(\mathrm{kN} \mathrm{m})$} \\
& EXP & CAL & (EXP-CAL)/CAL (\%) \\
\hline JD1 & 679 & 612 & 10.9 \\
JD2 & 614 & 556 & 10.4 \\
\hline
\end{tabular}

\section{Conclusions}

In this paper, two dismantle hollow beam components after service for 24 years were tested under four-point bending to failure. The test results were analyzed based on the static performance (such as deflection, strain, and cracks development) as well as ultimate capacity. The experimental results were compared to corresponding predicted values according to the design code GB 50010 and ACI 318. The following conclusions can be drawn:

(1) The bending process of the RC hollow beam went through the elastic phase to the elastic-plastic phase and to the final failure. The additional $7 \mathrm{~cm}$ leveling layer increased the yield and ultimate load of the component by about $11 \%$ and reduced the yield and ultimate deflection by $22 \%$ and $17 \%$, respectively.

(2) A quick assessment of loading capacity of bridge using crack height was proposed. When the crack height reached 0.70 times the beam height, the steel bar may enter the yield stage and the bridge should be repaired in time.

(3) The natural vibration frequencies of the beam changed slightly before plastic stage, but the modal amplitude increased with the increase of degree of damage, once the beam entered plastic stage.

(4) The actual flexural capacity was $10 \%$ larger than the calculated values. The predicted deflections according to GB50010 were consistent with the experimental values at about $200 \mathrm{kN}$; for the code ACI, as the loading force increases, the difference between the two gradually decreases. The maximum crack width predicted by the two codes was quite different from the test value, and a parameter correction method for the crack width prediction formula in the code was proposed.

\section{Data Availability}

The data used to support the findings of this study have not been made available because research project is in progress.

\section{Conflicts of Interest}

The authors declare that they have no conflicts of interest.

\section{Acknowledgments}

This research was funded by the Transportation Science and Technology Innovation Project of Shandong Province (Grant no. 2016B49). The authors greatly appreciate it.

\section{Supplementary Materials}

Supplementary materials are real-time data collected by the computer during the test. "CH001-CH008" are deflection of the JD1 beam; "CH009" is the applied load of the JD1 beam; 
"CH010-CH029" are rebar strain and concrete strain of the JD1beam. (Supplementary Materials)

\section{References}

[1] J. Q. Zhang, P. F. Li, Y. Mao, and Z. H. Dong, "The mechanical properties of reinforced concrete plate-girders when placed under repeated simulated vehicle loads," Materials, vol. 12, no. 11, Article ID 1831, 2019.

[2] X. Y. Sun, C. K. Huang, and G. F. Zhao, "Exprimental study of the influence of truck overloads on the flexural performance of bridge members," China Civil Engineering Journal, vol. 38, no. 6, pp. 35-40, 2005.

[3] S. B. Chase and L. Gáspár, "Modeling the reduction in load capacity of highway bridges with age," Journal of Bridge Engineering, vol. 5, no. 4, pp. 331-336, 2000.

[4] D. M. Frangopol, A. Strauss, and S. Kim, "Bridge reliability assessment based on monitoring," Journal of Bridge Engineering, vol. 13, no. 3, pp. 258-270, 2008.

[5] R. A. Miller, A. E. Aktan, and B. M. Shahrooz, "Destructive testing of decommissioned concrete slab bridge," Journal of Structural Engineering, vol. 120, no. 7, pp. 2176-2198, 1994.

[6] M. Maksymowicz, P. J. S. Cruz, and J. Bień, "Load capacity of damaged RC slab spans of railway-bridges," Archives of Civil and Mechanical Engineering, vol. 11, no. 4, pp. 963-978, 2011.

[7] N. Bagge, C. Popescu, and L. Elfgren, "Failure tests on concrete bridges: have we learnt the lessons?" Structure and Infrastructure Engineering, vol. 14, no. 3, pp. 292-319, 2018.

[8] J. L. Jorgensen and W. Larson, "Field testing of a reinforced concrete highway bridge to collapse," Transportation Research Record, Transportation Research Board, vol. 607, pp. 66-80, 1976.

[9] E. Lantsoght, C. De Boer, and D. Hordijk, "Collapse test and moment capacity of the ruytenschildt reinforced concrete slab bridge," Structure and Infrastructure Engineering, vol. 13, no. 9, pp. 1130-1145, 2017.

[10] K. A. Harries, "Structural testing of prestressed concrete girders from the lake view drive bridge," Journal of Bridge Engineering, vol. 14, no. 2, pp. 78-92, 2009.

[11] Y. Li, J. Zhang, Y. Chen et al., "Ultimate flexural capacity of a severely damaged reinforced concrete T-girder bridge," Journal of Bridge Engineering, vol. 22, no. 5, Article ID 05017003, 2017.

[12] P. N. Roschke and K. R. Pruski, "Overload and ultimate load behavior of posttensioned slab bridge," Journal of Bridge Engineering, vol. 5, no. 3, pp. 148-155, 2000.

[13] A. Bechtel, J. Mcconnell, and M. Chajes, "Ultimate capacity destructive testing and finite-element analysis of steel I-girder bridges," Journal of Bridge Engineering, vol. 16, no. 2, pp. 197-206, 2011.

[14] F. Seible and C. T. Latham, "Analysis and design models for structural concrete bridge deck overlays," Journal of Structural Engineering, vol. 116, no. 10, pp. 2711-2727, 1990.

[15] G. B. Tang, Y. Q. Xiang, and P. W. Guan, "Effect of deck pavement on mechanical performance of medium-span and short-span bridges," Journal of Highway and Transportation Research and Development, vol. 27, no. 12, pp. 94-98, 2010, in Chinese.

[16] JTJ 023, Code for Design of Highway Reinforced Concrete and Prestressed Concrete Bridges and Culverts, China Communications Press, Beijing, China, 1985.

[17] C. Q. Wang, Y. G. Shen, R. F. Yang et al., "Experimental study on failure mechanism of prestressed concrete $\mathrm{T}$ girder," Journal of Railway Science and Engineering, vol. 14, no. 11, pp. 2369-2376, 2017.
[18] A. E. Naaman, M. H. Harajii, and J. K. Wight, "Analysis of ductility in partially prestressed concrete flexural members," PCI Journal, vol. 31, no. 3, pp. 64-87, 1986.

[19] A. A. Abdelrahman, G. Tadros, and S. H. Rizkalla, "Test model for the first Canadian smart highway bridge," ACI Materials Journal, vol. 92, no. 4, pp. 451-458, 1995.

[20] P. Liang, X. L. Wang, C. H. Lou et al., "Rapid evaluation of load-bearing capacity of concrete beam bridge based on crack feature library," China Journal of Highway and Transport, vol. 27, no. 8, pp. 32-41, 2014.

[21] W. X. Zhang, X. L. Liu, B. Luo, and M. G. Li, "Quick assessment of loading capacity of bridge by cracking characteristics," Journal of Northeastern University (Natural Science), vol. 29, no. 9, pp. 1346-1349, 2008, in Chinese.

[22] A. K. Pandey and M. Biswas, "Damage detection in structures using changes in flexibility," Journal of Sound and Vibration, vol. 169, no. 1, pp. 3-17, 1994.

[23] GB50010, Code for Design of Concrete Structures, China Construction Industry Press, Beijing, China, 2010.

[24] ACI 318, Building Code Requirements for Structural Concrete and Commentary, American Concrete Institute, Farmington Hills, MI, USA, 2011.

[25] JTG B01, Technical Standard of Highway Engineering, China Communications Press, Beijing, China, 2014.

[26] Y. Q. Xiang, J. W. Xu, G. B. Tang, and H. H. Zhu, "Modified method for calculating crack width of reinforced concrete members and its field test," Journal of Highway and Transportation Research and Development, vol. 28, no. 2, pp. 45-51, 2011, in Chinese.

[27] S. P. Li and C. Song, "Mechanical performance tests and analysis of prestressed lightweight aggregate concrete hollow slab," Advances in Structural Engineering, vol. 22, no. 5, pp. 1-15, 2019.

[28] ACI-ASCE Committee 333, “Tentative recommendations for the design of composite beams and girder for buildings," $A C I$ Journal, vol. 57, no. 12, pp. 609-628, 1960. 